\title{
The Regional Impact of Wal-Mart Entrance: A Panel Study of the Retail Trade Sector in West Virginia
}

\author{
Michael J. Hicks and Kristy L. Wilburn*
}

\begin{abstract}
This paper examines the retail trade sector in 55 West Virginia counties from 1989 through 1998. A time-space recursive model evaluates the impact of the entrance of Wal-Mart stores in the county and in adjacent counties. This paper differs from earlier research in that it controls for endogeneity in the entrance decision of Wal-Mart in faster-growing counties, applies spatial analysis, and estimates impacts at the county level. This research finds a net increase in employment (55 jobs) and a mild increase in the number of firms (five) in the Retail Trade sector (SIC 52). The study supports the pull-factor explanation of retail trade growth. The paper concludes with further research recommendations.
\end{abstract}

\section{INTRODUCTION}

The putative economic impact of a discount store in a community has been hotly debated in communities across the U.S. throughout the past decade. Among the perceived impacts of these types of discounts stores, which we feel competent to address, include lower regional wages, capital outflows, and loss of independent, locally owned businesses. These costs are weighed against arguments relating to the benefits of increased efficiency, employment, and tax revenues. Less frequently discussed are the consumption benefits. Economists, for the most part, have been silent on these issues, feeling that the economies of scale inherent in a discount store and the success of local market mechanisms meant increased welfare effects for local communities. Simply, the matter was not investigated on a broad scale within the academic community.

The few studies that have been performed do not generate a consensus result. Nearly all work in this area has focused on the location of Wal-Mart stores in local communities since the mid-1980s. The earliest of these studies (Keon, Robb, and Franz 1989) performed a static comparison of economic conditions in 14 Missouri counties with and without Wal-Mart stores. These researchers found no evidence of a net negative impact of Wal-Mart location, instead finding increases in broad measures of income, retail employment and income, and sales tax revenues. At the retail sector level, they found that the overall number of stores had declined, but there were more employees and slightly higher payrolls. They did not note per capita wages in the retail sector, nor did they account for an entrance decision by Wal-Mart based in part on the growth rate of the community. This final problem plagues most studies in the literature. Simply, the question of

"Director of Research and Assistant Professor of Economics; and Director of Business Analyses; Center for Business and Economic Research, Lewis College of Business, Marshall University, Huntington, West Virginia. 
endogeneity in the growth variable in explicit or implicit modeling has not been adequately addressed: static analysis fails to capture the possibility that Wal-Mart stores enter counties with higher growth rates. This problem was addressed in a later paper (Ozment and Martin 1990), which found few significant positive effects of Wal-Mart in a sample of rural counties. The study examined population, income, number of establishments, per capita bank deposits, employment, sales revenue, and tax receipts. The authors suggested that Wal-Mart may have selected faster-growing counties for store locations, and that the mildly better performance of the economies in these counties was not likely caused by the store entrance.

A study of employment and wages in Maine (Ketchum and Hughes 1997) concluded that there was no evidence of a net negative impact in a sample of 12 counties with and 12 counties without Wal-Mart stores. Although a small observation set was employed, these findings were similar to the earlier studies. The impacts were not significant and the authors recognized the possibility that WalMart entered counties with higher growth rates. ${ }^{1}$ A broader study (Barnes and Connell 1996) examined regional variation in Wal-Mart impacts across several northeastern states. The study examined impacts on specific industries, finding a pattern of results. Barnes and Connell (1996) found 1) increased sales of general merchandise, but with the number of establishments unchanged; 2) little or no change in the number of food stores and sales; and 3) decreased auto and furniture sales and increased eating, apparel, and drug store sales. The authors sought to find patterns, not causation, and the results point to that effort.

Two historians conducted a study that evaluated the social and economic effect of Wal-Mart entrance in southern towns (Vance and Scott 1992). The study addressed several sticky issues, such as capital outflows and the benefits of locally owned firms. They concluded that the benefits Wal-Mart brought to the local communities outweighed the costs. ${ }^{2}$ More recently, a study of the impact of Wal-Mart Supercenters on supermarket concentration found both that Wal-Mart stores tended to enter in slower-growing markets and that the impacts on concentration and retail performance in food stores were minimal (Franklin 2001).

Perhaps the best known research on Wal-Mart impacts focused on small towns in Iowa (Stone 1995, 1997; Stone, Deller, and McConnon 1992). Stone's (1997) comparative study of 34 towns $(5,000-40,000$ pop.) examined changes in the same sets of variables as did the earlier studies, examining a metric known as the pull factor (the proportion of sales in a county as a proportion of statewide sales) in several industry sectors (see Harris and Shonkwiler 1997 for a review of the literature). The short-run effects pointed to Wal-Mart-induced increases (or slower decreases) in several sectors. This took the form of comparison between cities with

\footnotetext{
${ }^{1}$ This study is notable for its use of actual statistical analysis, not merely comparisons of growth rates. The authors used the difference-in-difference-in-difference method (Gruber 1994) to approximate second derivative analysis for functions whose empirical specifications were not continuous.

${ }^{2}$ The inclusion of a historical study in this review suggests the paucity of economic research on the subject. The weakness of the economic analysis by these authors (and their interpretation of the existing economic literature) highlights the problems that surround the analysis of discount stores. For example, the authors write, "Walton hit upon another innovation...that by lowering his price per item he could sell a greater quantity of goods" (Vance and Scott 1994, p. 8, our italics).
} 
and without Wal-Mart stores. The author suggested that long-term growth rates would diverge much more modestly than the pronounced short-run effects. He attributed this, in part, to the travel of shoppers to the Wal-Mart area from adjoining counties. Changes in the pull factors were used to capture this intercounty movement of consumers. Stone's work was primarily aimed at describing the local effects of Wal-Mart entrance by focusing on large samples of towns, and is the most extensive and analytical of the existing literature. This study went farther in establishing retail strategies for local stores facing Wal-Mart entrance, expanding this section into a widely read book on retail strategies for locally owned businesses competing with discount stores. ${ }^{3}$

In this study, we evaluate whether or not the pull-factor changes Stone introduced can be approximated through variations in the sample employed in our panel regression analysis. We examine whether the entrance of Wal-Mart in poor counties, with fewer retail outlets, results in stronger economic impacts than in more populous and affluent counties. This should imply the existence of a pullfactor effect that would be more apparent in smaller, more rural counties with fewer retail alternatives.

The impact of Wal-Mart entrance has not been evaluated using newer econometric methods, nor has there been a study that attempts to control for endogeneity in the growth component. We seek to remediate this omission by evaluating the impact of Wal-Mart stores in southwestern West Virginia. Our study differs from Stone's research in that it observes a longer period of activity (10 years), employs more modern analytical methods, and extends the analysis to include the spatial effects. Also, we enjoy the benefit of his extensive contribution to this area.

\section{WAL-MART IN WEST VIRGINIA}

Wal-Mart incorporated in West Virginia late in its corporate life (August 1989) and as of the summer of 1999 had 18 store locations and three supercenters and was the largest employer in the state, with over 5,700 employees. ${ }^{4}$ The counties we evaluate are both rural and urban, but share slow growth and relatively high unemployment and, during our sample period of 1989-1998, most continued to suffer from net population declines. Indeed, out-migration, as a consequence of the sluggish economy, was among the chief policy concerns in the state legislature during this period. While we have specific analytical methods to determine whether Wal-Mart entered faster-growing counties within the region, it is clear that West Virginia would have ranked near the bottom on any growth-related entrance decision.

It appears that Wal-Mart decisions to enter West Virginia markets are based on population size, not growth or higher per capita income. This finding is supported by a study of Wal-Mart Supercenters, which found that entrance was negatively correlated with income levels in the MSAs studied (Franklin 2001). All 3Stone, Kenneth E. Competing with the Retail Giants. New York: John Wiley and Sons, 1995. This book was translated into Japanese and published by the Tuttle-Mori Agency in Tokyo in 1997.

4The company claims $\$ 10$ million in local taxes and almost \$47 million in state tax revenues per year. 
but two of the West Virginia MSA counties are much below the national average in per capita income. ${ }^{5}$ This notion is also reinforced through examination of the counties where Wal-Mart located. To capture a wide population size, all sites are easily visited and seem to be centrally located. Also, as we will address later, it appears that mass discount-type merchandisers (e.g., Target, Kmart, and WalMart) are driven to enter markets, in part, based on rival location. That partially explains why there were, in 1996 for example, the same number of Wal-Mart stores and Kmart stores in West Virginia. What we seek to determine is the net economic impact within the counties where Wal-Mart located. This study will differ not in that question, but instead in the method of answering-by relying on dynamic growth effects, not static comparisons. This study incorporates the spatial dimension both through an explanatory variable and through recursive and contemporaneous spatial autoregressive functions. This study looks at a longer time period than any earlier study and focuses attention at the county level. In these regards, this study differs from the previous research examining discount store impacts on local communities.

\section{DATA AND ESTIMATION}

Data for this study were obtained from the Bureau of the Census (Standard Industrial Classification employment, wages, and number of firms), the Bureau of Labor Statistics (unemployment rates; civilian labor force figures; personal income; and consumer price index, all urban consumers), and from the individual Wal-Mart stores in the study (entrance year and location). All data are annual from 1988 through 1998.

As outlined earlier, a chief criticism of several studies of the local impact of Wal-Mart or similar retailers was their inability to decompose the retailer's effect on the local community from unrelated economic effects. This potential problem is especially critical in a study that encompasses entrance of a firm during the sample period. The question is, simply, was the decision to enter the market by the retailer independent of the rate of growth of the community? This simple endogeneity issue potentially clouds any further analysis. Accordingly, we seek to establish that Wal-Mart location decisions are independent of the rate of growth of the individual counties in which the Wal-Mart stores are located (within our sample). To begin this test, we compared the growth rates of personal income between the Wal-Mart and no-Wal-Mart counties from 1988 through 1998 for West Virginia's 55 counties. There was no statistical difference between the two at any acceptable level of significance.

We examined the entrance decision at each location by constructing a probit model in which the entrance decision $[0,1]$ was tested on the county's current one- and two-year lagged growth rates. We counted entrance and an upgrade to a Wal-Mart Supercenter as decisions to enter. The results were invariant to traditional distributional assumptions (normal, logistic, binomial, or negative binomial)

5Two West Virginia counties are within the Washington, D.C., MSA and are higher-growth counties. 
and suggest that growth and lagged growth had no significant effect on the decision to enter. From the Franklin (2001) study and our analysis, we feel secure in assuming that growth rates played no meaningful part in Wal-Mart's decision to enter a market. This eliminates the potential endogeneity issue and permits testing of our impact model.

In estimating the impact of Wal-Mart on each county, we seek to incorporate both time and spatial effects of store entrance on a relatively small set of variables (employment and net number of firms in the retail sector). Given this specificity of our hypothesis, a time-space dynamic model (Anselin 2001) appears most appropriate. The model takes the form

$$
y_{i, t}=x \beta+\rho\left[\tilde{W} y_{i}\right]+\theta\left[\tilde{W} y_{i, t-1}\right]+\phi y_{i, t-n}+\varepsilon_{i, t}
$$

where $x \beta$ is an $n \times m$ matrix of explanatory variables, $\rho$ is an $m \times 1$ spatial autoregressive vector, $\theta$ is an $m \times 1$ space-recursive vector, and $\phi$ is the traditional autoregressive coefficient. $\mathrm{W}$ is an $\mathrm{n} \times \mathrm{n}$ first-order contiguity matrix with normalized row components and $\varepsilon_{i, t}$ is the standard error component assumed to be iid $\rightarrow \mathrm{N}\left(0, \sigma^{2}\right)$.

The spatial autoregressive and spatial recursive components are a point of departure from the traditional AR(1) model with contemporaneous exogenous variables otherwise illustrated. In estimating a spatial component, we employ a weighted and normalized set of observations of the dependent variable in contiguous counties in time $t$. The recursive component employs the same estimate in time $t-1$, so is a spatial analog to a recursive model in time series analysis.

This model was tested on a panel series of 55 cross sections over 11 years. The assumptions employed in testing panel series involve restrictions on crosssectional fixed effects and allowances for time-varying and cross-sectional (random) effects. Both of these models offer limited suitability since fixed-effects estimators are not asymptotically consistent in a spatial setting (Anselin 2001) and random-effects models preclude a straightforward incorporation of the autoregressive component. The selection of one of these two alternatives has been subject to much debate in the literature (see Baltagi 1995) beyond even the spatial and autoregressive incompatibility of the estimators. A panel model with a common intercept appeared to be the most appropriate specification. This specification permits both cross-sectional and time-varying components to be estimated using the direct time-space dynamic model. All standard errors were White-washed with White's heteroscedasticity invariant variance-covariance matrix.

The matrix of explanatory variables included a presence dummy for WalMart in each county. Also, this variable was calculated for adjacent counties. Macroeconomic and labor market variables included the unemployment rate and civilian labor force for each county. The dependent variables reported here were employment, wages, and the number of firms in retail trade in each county. Selected results appear in Table 1. 
TABLE 1

Employment and Net Firm Effects of Wal-Mart Entrance

\begin{tabular}{lcccc}
\hline Variable & $\begin{array}{c}\text { employment in } \\
\text { retail trade }\end{array}$ & $\begin{array}{c}\Delta \text { (employment in } \\
\text { retail trade) }\end{array}$ & $\begin{array}{c}\text { \# of firms in } \\
\text { retail trade }\end{array}$ & $\begin{array}{c}\Delta \text { (\# of firms in } \\
\text { retail trade) }\end{array}$ \\
\hline $\mathrm{c}$ & $-170.47^{* *}$ & -0.89 & -6.91 & $1.22^{* * *}$ \\
Wal-Mart presence & $(-2.20)$ & $(-0.36)$ & $(-0.82)$ & $(3.07)$ \\
& $54.56^{* *}$ & $49.06^{* * *}$ & $4.904^{* *}$ & 0.72 \\
Number of Wal-Mart stores & $(2.34)$ & $(6.81)$ & $(2.55)$ & $(1.32)$ \\
in adjacent counties & $-0.07^{* * *}$ & 0.00015 & $-0.0054^{* * *}$ & -0.0000479 \\
County unemployment rate & $(-8.66)$ & $(0.85)$ & $(-7.27)$ & $(-1.24)$ \\
& 0.35 & -0.05 & 0.03 & $-0.08^{* * *}$ \\
Civilian labor force & $(1.57)$ & $(-0.71)$ & $(0.74)$ & $(-4.31)$ \\
& $0.08^{* * *}$ & $0.001^{* * *}$ & $0.003^{* * *}$ & $-0.0000983^{* *}$ \\
$\rho$ & $(14.92)$ & $(4.25)$ & $(4.25)$ & $(-2.06)$ \\
& $0.06^{* * *}$ & $0.04^{* * *}$ & $0.14^{* *}$ & $0.12^{* * *}$ \\
$\theta$ & $(10.57)$ & $(11.78)$ & $(13.31)$ & $(9.96)$ \\
& $-0.01^{* * *}$ & $-0.009^{* * *}$ & $0.025^{* * *}$ & $0.023^{* *}$ \\
$\phi(t-1)$ & $(-3.70)$ & $(-2.59)$ & $(2.57)$ & $(2.27)$ \\
& $0.90^{* * *}$ & $-0.17^{* * *}$ & $0.74^{* * *}$ & $-0.22^{* * *}$ \\
$\phi(t-2)$ & $(19.89)$ & $(-3.34)$ & $(19.24)$ & $(-5.48)$ \\
& $0.11^{* *}$ & $-0.16^{* * *}$ & $0.23^{* * *}$ & 0.001 \\
\hline Adjusted $R^{2}$ & $(2.17)$ & $(-2.70)$ & $(6.31)$ & $(0.03)$ \\
D-W statistic (pooled) & 0.98 & 0.08 & 0.98 & 0.07 \\
\hline
\end{tabular}

***Significant to the 0.01 level.

** Significant to the 0.05 level.

* Significant to the 0.10 level.

These results tell a clear story about the effect of Wal-Mart on local employment and the number of firms in retail trade. First, although the estimated parameter was non-negative, no specification revealed a statistical or economically significant impact on per capita wages in retail trade. That result is not illustrated. However, within this narrow industrial classification, this regression indicates a one-time increase in jobs attributable to Wal-Mart of over 54 positions. This occurs even with controls for the overall county economic performance. Likewise, these results suggest an adjacent Wal-Mart location may lower employment in a county, but at an insignificantly low level. Not surprisingly, the spatial effects are positive in the retail trade sector, both contemporaneously and recursively. The regression in first differences generated similar results. Interestingly, it appears that the bulk of net new employment generated by a Wal-Mart entrance occurs in the first year. This one-time increase in jobs appears permanent for at least three years.

The regressions on the number of firms and the change in the number of firms indicated a modest positive effect by Wal-Mart. Following the location of Wal-Mart in the area, the total number of firms in retail trade increased by roughly five firms. Again, this was a one-time, but lasting, increase in the net number of firms. The negative impact on the net number of firms attributable to a Wal-Mart entrance was statistically, but not economically, significant.

Previous research has found a slight (often insignificant) net employment increase and increased numbers of firms outside the retail trade sector (e.g., eating and drinking establishments, gasoline service stations, etc.). Nowhere have we 
seen results that show an increased number of retail trade establishments following the entrance of a large chain store. This is net, not gross, number of firms. There are two possible explanations for these results. The first is that Wal-Mart clusters explain much of the increase. When Wal-Mart locates in an area, several smaller establishments also tend to locate nearby. The second, and more likely, explanation is that the existence of Wal-Mart draws a larger shopping crowd from other locations. ${ }^{6}$ The extreme rural conditions in many of the sampled counties suggest that consumers may shop at local Wal-Mart locations instead of traveling to more urban areas. This pull-factor effect attracts more local retail trade (Stone 1997; Harris and Shonkwiler 1997).

When we examined this on rural counties the results were remarkably unchanged (though admittedly most of West Virginia counties are rural). In urban counties, the Wal-Mart effect dropped from significance (another finding supporting Franklin's 2001 work on supermarkets). This suggests that the impacts were more pronounced in rural counties than in urban counties. This strongly supports the explanation that pull factor leads to an increase in new retail establishments. ${ }^{7}$

These results were restricted to the effect on total employment and establishments in retail trade. It seems intuitive that the effect of Wal-Mart on other sectors will be positive (e.g. construction, whole trade, eating establishments, and services, and on gasoline service stations) where Wal-Mart does not typically offer rival goods and services. Earlier studies have mostly borne this out. Neglecting these other sectors is also a data necessity since suppression of key data by the Bureau of the Census affected each of the other critical sectors we could potentially examine. ${ }^{8}$ Of interest are the gross employment flows and the change in the number of gross establishments both before and after the beginning of this sample period. These data interest researchers because they describe any change in the volatility and duration of employment and number of firms that could be attributable to the entrance of Wal-Mart stores. It is likely, given the modest net increase in retail trade employment and establishments, that there is not a large gross decline in these data. ${ }^{9}$ Indeed, the simple increase in net employment in these counties (the majority of which experienced net population declines during the sample period) most likely led to much shorter periods of unemployment. These are empirical questions, however, and ones that shall remain unanswered here, since the data necessary to answer these questions are prohibitively expensive or suppressed. ${ }^{10}$

The total direct economic impact of the seven Wal-Mart stores in southern West Virginia can be calculated based on the estimates of the net increase in

\footnotetext{
${ }^{6}$ These two effects may be related in that the Wal-Mart cluster firms must expect some overflow of shoppers to the site.

7Stone's conclusions appear substantially supported by these results.

8The use of sales tax data from the West Virginia Department of Revenue may be exploited in later research.

9 Our estimates are slightly smaller than the Wal-Mart claims of gross job effects in these counties. However, this is speculative and will likely remain so given the suppression of data.

${ }^{10}$ Bureau of the Census data estimates for the barest of these data exceed $\$ 750$ per year. The richer set of data may exceed $\$ 4,000$ per year and we require at least nine years of the data.
} 
employment and retail trade establishments using standard RIMS-II multipliers. ${ }^{11}$ There is an additional effect due to the location of Wal-Mart and that is an increase in local sales (fewer cross-border imports). This effect should actually increase the value of the multiplier for each county in which a Wal-Mart is located. Of course, this may not be a net change for the region as a whole. This again is the pull-factor effect, which dissipates as more Wal-Mart stores enter the market. That is probably why Stone noted more modest increases in the pull-factor changes over time.

\section{CONCLUSIONS}

The varied estimates of the economic impact of Wal-Mart in earlier studies indicated a need for more research. Likewise, the analytical methods that do not control for regional macroeconomic changes are incomplete. Also, we do not believe that the studies that fail to at least acknowledge the net benefits of WalMart (both in consumption and production) provide valuable insight to the effect. ${ }^{12}$ This indicts the economic benefit of most of the studies (other than Ketchum and Hughes 1997) that have been performed. This is a narrow criticism, however, and several of these studies (especially Stone's) seek to answer other important questions. Still, we find the existing literature on this subject clearly wanting in method and scope.

In our study, the data on employment changes and net establishment changes strongly supports the notion, due to the entrance of Wal-Mart in the county, that consumers are remaining closer to home when making retail purchases. This effect can only continue to extend to the point where there is a Wal-Mart, or other discount merchandiser, in every county. This explains part of the increase in retail trade; the remainder was explained empirically by the changes in population and the unemployment rate in the State. In every case however, the impact on this sector of Wal-Mart was much more pronounced than the growth of the economy (which has not been robust). This result is important to researchers interested in explaining the pattern of regional economic growth, especially in rural communities. It may be of interest to policy makers intent on controlling the entrance of Wal-Mart stores in local areas. There is clearly a net benefit to employment and wages in having a Wal-Mart locate in a county. The net benefit is really the only economically justifiable measure in this type of analysis.

To many who read this study, our conclusion may prove indigestible. The criticism of Wal-Mart entrance is not often couched in economic analysis, but in sociological analysis. We prefer to remain silent on that subject. We would note

\footnotetext{
${ }^{11}$ These RIMS-II or Regional Impact Multiplier Series from the Bureau of Labor Statistics are the common impact tool for local economic analysis.

${ }^{12}$ We also feel that much of the literature by other social scientists on this subject (left unreviewed in this paper) could be improved. Specifically, there are a number of studies that infer labor market impacts that presuppose average wage rates are independent of simple productivity measures. We feel that established analytical tools should be applied to research on the labor force of discount stores. Laying all coyness aside, the comparison of retail wages with other sectors is often performed without control variables for skill level, time restrictions, and individual preferences. Similarly, the choice of production mix in an economy is endogenous to any specification of aggregate demand. Many of the studies of Wal-Mart that find dissatisfied workers (or retail workers who are inexplicably satisfied with their low-paying jobs) implicitly suppose that the mix of goods in an economy is exogenously determined in a model of aggregate output.
} 
that the criticisms leveled against Wal-Mart are a familiar refrain. In the late nineteenth century, they were launched against chain five-and-dime stores throughout the Midwest. In the 1920s, Sears and Roebuck suffered through similar criticisms of their low-priced mail-order services. Indeed, local monopolies may have a great deal to lose from entrance by firms that enjoy, and exploit, economies of scale.

\section{REFERENCES}

Anselin, Luc. "Spatial Econometrics." In B.H. Baltagi, Econometric Analysis of Panel Data. 2d ed. New York: John Wiley, 2001.

Baltagi, B.H. Econometric Analysis of Panel Data. New York: Wiley, 1995.

Barnes, N.G., and A. Connell. "Regional Differences in the Economic Impact of Wal-Mart." Business Horizons 39 (4) (1996), 21-26.

Franklin, Andrew W. "The Impact of Wal-Mart Supercenters on Supermarket Concentration in U.S. Metropolitan Areas." Agribusiness 17 (1) (Winter 2001), 105-114.

Gruber J. "The Incidence of Mandated Maternity Benefits." American Economic Review 84 (3) (1994), 622-641.

Harris, Thomas R., and J. Scott Shonkwiler. "Interdependence of Retail Businesses." Growth and Change 28 (4) (1997), 520-533.

Keon, Thomas, Edward Robb, and Lori Franz. "Effect of Wal-Mart Stores on the Economic Environment of Rural Communities." Columbia: Business and Public Administration Research Center and College of Business and Public Administration, University of Missouri, 1989.

Ketchum, B.A., and J.W. Hughes. "Wal-Mart and Maine: The Effect on Employment and Wages." Orono: University of Maine, 1997. Mimeo.

Ozment, J., and G. Martin. "Changes in the Competitive Environments of Rural Trade Areas-Effects of Discount Retail Chains." Journal of Business Research 21 (1990), 277-287.

Stone, K.E. "Impact of the Wal-Mart Phenomenon on Rural Communities." Increasing Understanding of Public Problems and Policies. Oak Brook, Ill.: Farm Foundation, 1997.

. Competing with the Retail Giants. New York: John Wiley and Sons, 1995.

Stone, K.E., S.C. Deller, and J.C. McConnon, Jr. "The New Retail Environment in Maine." The Maine Business Research Report 3 (1) (September 1992).

Vance. S., and R.V. Scott. "Sam Walton and Wal-Mart Stores, Inc.: A Study in Modern Southern Entrepreneurship." The Journal of Southern History 58 (2) (1992), 231-252.

. Wal-Mart: A History of Sam Walton's Retail Phenomenon. New York: Twayne Publishers, 1994. 
